\title{
Trichosanthin enhances the antitumor effect of gemcitabine in non-small cell lung cancer via inhibition of the PI3K/AKT pathway
}

\author{
NAREN TUYA ${ }^{1-3}$, YADI WANG ${ }^{1,2}$, LANMEI TONG $^{3}$, WEISHI GAO ${ }^{3}$, RONG YU $^{4}$ and LIYING XUE ${ }^{3}$ \\ ${ }^{1}$ Department of Biology, Southern Medical University, Guangzhou, Guangdong 510515; ${ }^{2}$ Department of Radiation Oncology, \\ General Hospital of Beijing Military Region, Beijing 100700; ${ }^{3}$ Department of Chemotherapy Oncology, \\ Inner Mongolia People's Hospital; ${ }^{4}$ Department of Radiation Oncology, Inner Mongolia Cancer Hospital, \\ Hohhot, Inner Mongolia 010020, P.R. China
}

Received December 19, 2016; Accepted July 14, 2017

DOI: 10.3892/etm.2017.5286

\begin{abstract}
Gemcitabine (GEMZ) is the first-line therapy used against non-small cell lung cancer (NSCLC), and studies have focused on investigating the potential effects of agents combined with GEMZ to enhance the anticancer efficacy in NSCLC. Previous studies have reported that trichosanthin (TCS) has various physiological and pharmacological effects, including anti-human influenza virus enzymes, inhibition of protein synthesis and antitumor activity. The purpose of the present study was to investigate if TCS enhanced the antitumor effects of GEMZ in NSCLC. MTT assay demonstrated that TCS significantly enhanced the cytotoxic effect of GEMZ ( $\mathrm{P}>0.05)$. Furthermore, a propidium iodide/Annexin V staining assay revealed that TCS exerted its pharmacological effect by increasing the apoptotic population. In addition, western blot analysis demonstrated that the combination treatment of TCS with GEMZ further decreased the expression level of phosphoinositide 3-kinase (PI3K) and AKT via regulating the expression of insulin growth factor. The results of the present study demonstrated that TCS enhanced the cytotoxic and apoptotic effects of GEMZ in A549 cells via regulating the PI3K/AKT pathway. In conclusion, these observations may provide a potential rational basis for a combination strategy for chemotherapy treatment of NSCLC.
\end{abstract}

\section{Introduction}

Lung cancer is prevalent worldwide and is the leading cause of cancer-related mortality (1). Non-small cell lung cancer

Correspondence to: Dr Yadi Wang, Department of Radiation Oncology, General Hospital of Beijing Military Region, 5 Dongsishitiao Nanmen Warehouse, Beijing 100700, P.R. China E-mail: yadiwang_smu@126.com

Key words: trichosanthin, gemcitabine, non-small cell lung cancer, apoptosis, drug resistance
(NSCLC) accounts for $>80 \%$ of all lung cancer cases (1-3). Furthermore, the prognosis of NSCLC is poor, with a 5-year survival rate of $<15 \%$ (4). Meanwhile, $>10 \%$ of patients with NSCLC are associated with epidermal growth factor receptor (EGFR) mutations (5).

Gemcitabine (GEMZ) is the first-line therapy against NSCLC that has been used for the past 10 years. Previous studies have demonstrated that it functions against NSCLC as a single agent $(6,7)$. Furthermore, studies have focused on investigating the potential effect of agent combination with GEMZ to enhance the anticancer efficacy in NSCLC patients $(8,9)$. However, cellular drug resistance is a major issue that often limits the efficacy of GEMZ chemotherapy (10). Therefore, an increased understanding of target therapy has revealed numerous potential therapeutic strategies, including combined GEMZ with carboplatin against NSCLC (11), combined GEMZ with abraxane against NSCLC (12) and combined piceatannol with GEMZ against NSCLC (10).

Trichosanthin (TCS) is a traditional Chinese medicine that is isolated from the root tuber of Trichosanthes kirilowii Maxim (13). It was reported that TCS has various pharmacological and physiological effects, including an anti-human influenza virus enzyme, inhibition of protein synthesis, neurotoxicity and anti-tumor activity (14-19). Additional studies have demonstrated that TCS may regulate numerous signaling pathways, such as mitogen-activated protein kinase family proteins, including p38, extracellular signal-regulated kinase (ERK), c-Jun N-terminal kinases, proapoptotic protein B-cell lymphoma 2; and inflammation-related factors, including nuclear factor $-\kappa \mathrm{B}(\mathrm{NF}-\kappa \mathrm{B})$, inhibitor of $N F-\kappa \mathrm{B}$, and cyclooxygenase-2 (20-23). Furthermore, TCS also possesses antitumor activity against the NSCLC A549 cell line (24).

The purpose of the present study was to investigate whether TCS could increase the antitumor effect and decrease drug resistance of GEMZ in NSCLC. A549 human NSCLC cells were used as a model and treated with a combination of GEMZ and TCS to assess cell viability and apoptosis, and to understand the underlying molecular mechanism. 


\section{Materials and methods}

Reagents. TCS and GEMZ were purchased from Sigma-Aldrich (Merck KGaA, Darmstadt, Germany) with a purity of $>98 \%$. Both drugs were dissolved in dimethylsulfoxide (DMSO) and diluted by Dulbecco's modified Eagle's medium (DMEM; Invitrogen; Thermo Fisher Scientific, Inc., Waltham, MA, USA), and the final concentration of DMSO was kept $<0.05 \%$ in the cell culture in order to have no detectable effects on cell growth and viability. MTT was purchased from Sigma-Aldrich (Merck $\mathrm{KGaA}$ ). Insulin-like growth factor I (IGF1) was purchased from R\&D Systems, Inc. (Minneapolis, MN, USA). All chemical reagents in the present study were of analytical reagent grade.

Cells and culture. A549 cells were purchased from American Type Culture Collection (Manassas, VA, USA). The cells were cultured in DMEM supplemented with $10 \%$ fetal bovine serum, penicillin $\left(10^{5} \mathrm{U} / \mathrm{l}\right)$ and streptomycin $(100 \mathrm{mg} / \mathrm{l})$ (Hyclone, Logan, UT, USA) in a humidified atmosphere of $37^{\circ} \mathrm{C}$ containing $5 \% \mathrm{CO}_{2}$.

MTT cell viability assay. A549 cells were plated at a density of $1 \times 10^{4}$ cells/well into 96 -well cell culture plates (Corning Incorporated, Corning, NY, USA) and cultured in a humidified atmosphere of $37^{\circ} \mathrm{C}$ containing $5 \% \mathrm{CO}_{2}$ for $24 \mathrm{~h}$. Next, the cells were treated with TCS $(0-25 \mu \mathrm{M})$ for $24 \mathrm{~h}$ at $37^{\circ} \mathrm{C}$, or cells were treated with different concentrations of GEMZ $(0-10 \mu \mathrm{M})$, with or without $20 \mu \mathrm{M}$ TCS for $24 \mathrm{~h}$ at $37^{\circ} \mathrm{C}$. In total, $24 \mathrm{~h}$ later, the cells were rinsed twice using ice-cold PBS and incubated in $100 \mathrm{ml} 0.5 \mathrm{mg} / \mathrm{ml}$ MTT solution for $3 \mathrm{~h}$ at room temperature. The crystal was dissolved in $150 \mu \mathrm{l}$ DMSO and the optical density (A490 nm) was measured using a microplate reader. Finally, the cell inhibitory rate was calculated using the following formula: Inhibitory rate $(\%)=\left(\mathrm{A}_{490} \mathrm{DMSO}-\mathrm{A}_{490} \mathrm{sample}\right) /\left(\mathrm{A}_{490} \mathrm{DMSO}-\mathrm{A}_{490}\right.$ blank $) \times 100$.

Observation of morphological changes. The cells were cultured and treated with GEMZ $(0-10 \mu \mathrm{M})$ with or without TCS $(20 \mu \mathrm{M})$ for $48 \mathrm{~h}$ at $37^{\circ} \mathrm{C}$, and the cellular morphology was observed using a phase contrast microscope (Olympus America, Inc., Center Valley, MA, USA) at magnification, x400.

Apoptosis measured by flow cytometry. Cell apoptosis was performed using an Annexin V/propidium iodide (PI) staining assay (Sigma-Aldrich; Merck KGaA). The cells were treated with $20 \mu \mathrm{M}$ TCS, $2.23 \mu \mathrm{M}$ GEMZ or a combination of both in 6-well plates for $48 \mathrm{~h}$ at room temperature. The cells were then lysed using cell lysis buffer (Cell Signaling Technology, Inc., Danvers, MA, USA) and centrifuged at 12,000 $\mathrm{x} g$ for $10 \mathrm{~min}$ at $4^{\circ} \mathrm{C}$. Then the cells were washed with PBS three times. Subsequently, the cells were fixed in $70 \%$ ethanol overnight at room temperature and stained with a mixture of PI containing $20 \mu \mathrm{g} / \mathrm{ml}$ RNase (Sigma-Aldrich; Merck KGaA) at $37^{\circ} \mathrm{C}$ for $30 \mathrm{~min}$. Finally, the cells were analyzed by flow cytometry (BD Biosciences, Franklin Lakes, NJ, USA). Data were analyzed using FlowJo software version 10 (FlowJo LLC, Ashland, OR, USA).

Western blot analysis. A549 cells were treated with $2.23 \mu \mathrm{M}$ GEMZ combined with or without $20 \mu \mathrm{M}$ TCS for $48 \mathrm{~h}$ at $37^{\circ} \mathrm{C}$, or cells were pre-treated with $0.5 \mu \mathrm{M}$ BMS-754807 for $24 \mathrm{~h}$, then treated with GEMZ and TCS for $48 \mathrm{~h}$ at $37^{\circ} \mathrm{C}$. Next, the adherent and floating cells were collected and centrifuged at $1,000 \mathrm{xg}$ for $10 \mathrm{~min}$ at room temperature and lysed with radioimmunoprecipitation assay lysis buffer (Beyotime Institute of Biotechnology, Haimen, China) supplemented with phenylmethylsulfonyl fluoride $(1 \mathrm{mM})$ for $30 \mathrm{~min}$ at $4^{\circ} \mathrm{C}$. Secondly, the suspension was centrifuged at $12,000 \mathrm{x}$ g for $10 \mathrm{~min}$, and the supernatant was collected. The protein concentration was detected using a Bio-Rad protein assay reagent (cat no. 500-0001; Bio-Rad Laboratories, Inc., Hercules, CA, USA). Equal amounts $(30 \mu \mathrm{g})$ of total protein were separated by $12 \%$ SDS-PAGE and transferred onto a Millipore Immobilon ${ }^{\circledR}-\mathrm{P}$ Transfer Membrane (EMD Millipore, Billerica, MA, USA). The membranes were blocked with $3 \%$ bovine serum albumin (Sigma-Aldrich; Merck KGaA) for 30 min at room temperature. The membranes were incubated with primary antibodies against phosphorylated (p)-phosphoinositide 3-kinase (PI3K) p85 (\#4428), p-AKT (\#4060), p-ERK (\#4370), ERK (\#4695) and GAPDH ( $\# 3683$ ) for $2 \mathrm{~h}$ at room temperature. The primary antibodies were obtained from Cell Signaling Technology, Inc., and used at 1:1,000 dilution. Then, the membranes were incubated with HRP-linked secondary antibody (\#7075; 1:1,000 dilution, Cell Signaling Technology, Inc.) for $1 \mathrm{~h}$ at room temperature. The expression levels of target proteins were visualized by electrochemiluminescence (Thermo Fisher Scientific, Inc.). The densitometry of proteins was analyzed with Quantity One version 4.6.2 (Bio-Rad Laboratories, Inc.).

Statistical analysis. To determine statistical significance between groups, all results and data were detected in at least three separate experiments. All data were analyzed using SPSS (version 13.0; SPSS, Inc., Chicago, IL, USA). Student's $\mathrm{t}$-test was used to compare two groups and one way analysis of variance and Dunnett's post-hoc test was used to analyze multiple group comparisons. $\mathrm{P}<0.05$ was considered to indicate a statistically significant difference. All data were expressed as the mean \pm standard deviation.

\section{Results}

TCS enhances the cytotoxicity of GEMZ. A549 cells were treated with different concentrations of TCS ranging between 0 and $25 \mu \mathrm{M}$. The results of the MTT assay demonstrated that TCS had no significant cell growth inhibitory effect on A549 cells (Fig. 1A). However, the MTT assay indicated that GEMZ suppressed A549 cell growth in a concentration-dependent manner (Fig. 1B). Additionally, the half maximal inhibitory concentration for $48 \mathrm{~h}$ GEMZ treatment was $2.23 \mu \mathrm{M}$. Since treatment with TCS alone had no toxicity, a higher dose of $20 \mu \mathrm{M}$ was selected as a combination strategy. The results indicated that the inhibitory effect on cell viability of different concentrations of GEMZ was significantly enhanced when cells were treated with $0.3(\mathrm{P}<0.05), 1(\mathrm{P}<0.01)$ or $3 \mu \mathrm{M}$ $(\mathrm{P}<0.01)$ GEMZ combined with $20 \mu \mathrm{M}$ TCS compared with the use of GEMZ alone (Fig. 1B). The results of the changes in cell morphology were consistent with the cell viability assay (Fig. 1C). These data indicated that TCS enhanced the cytotoxicity of GEMZ on NSCLC A549 cells. Since the combination of $20 \mu \mathrm{M}$ TCS with $2.23 \mu \mathrm{M}$ GEMZ had 

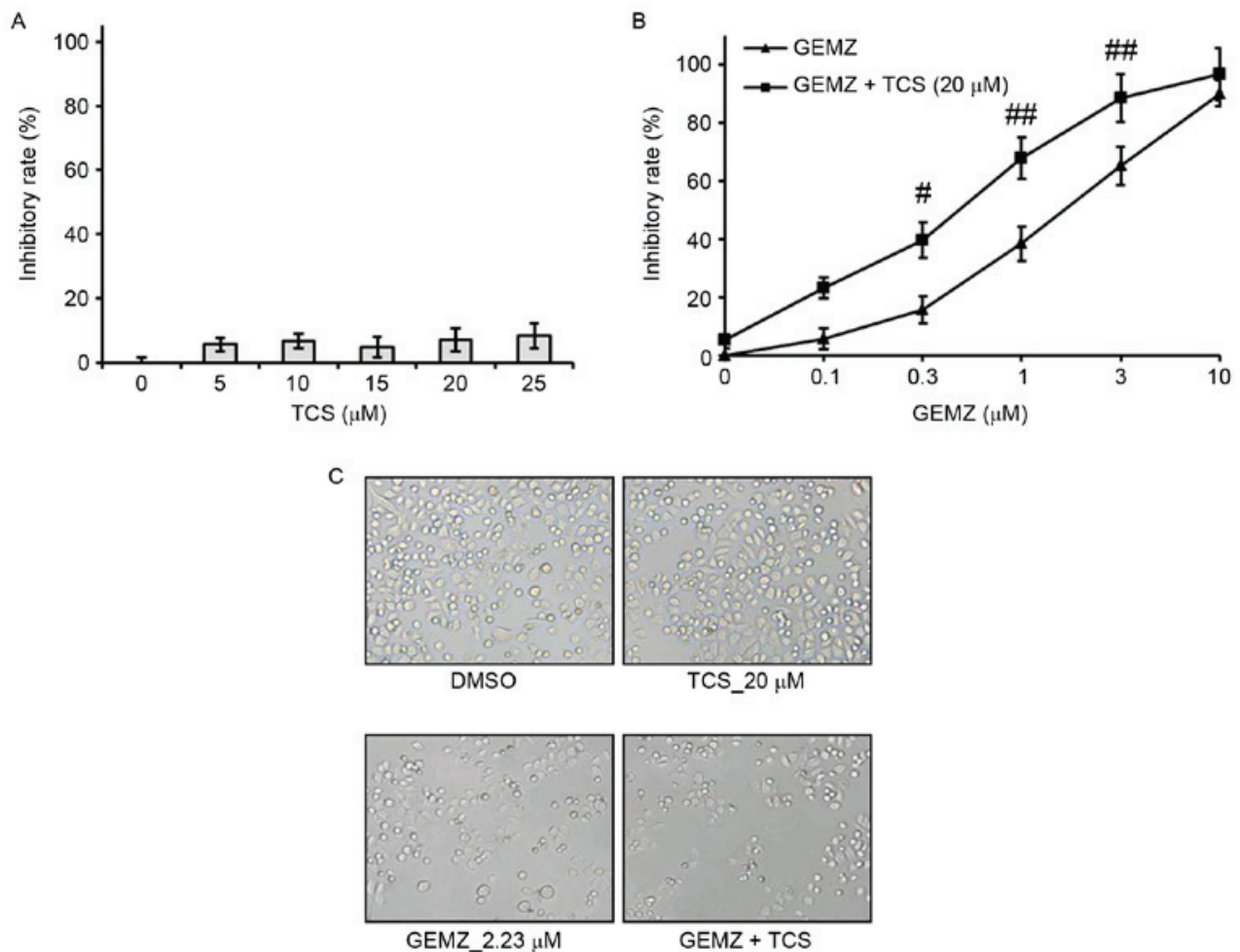

Figure 1. Effect of GEMZ and TCS on NSCLC A549 cells. Following the indicated treatment of (A) TCS or (B) GEMZ or combination treatment with GEMZ and TCS, the inhibitory rate was assessed by MTT assay. (C) Morphological changes of A549 cells were observed (magnification, x200). Results are expressed as the mean \pm standard deviation for more than three independent experiments. TCS, trichosanthin; GEMZ, gemcitabine; DMSO, dimethyl sulfoxide. ${ }^{\sharp P}<0.05$, ${ }^{\# \prime} \mathrm{P}<0.01$ vs. GEMZ treatment group.
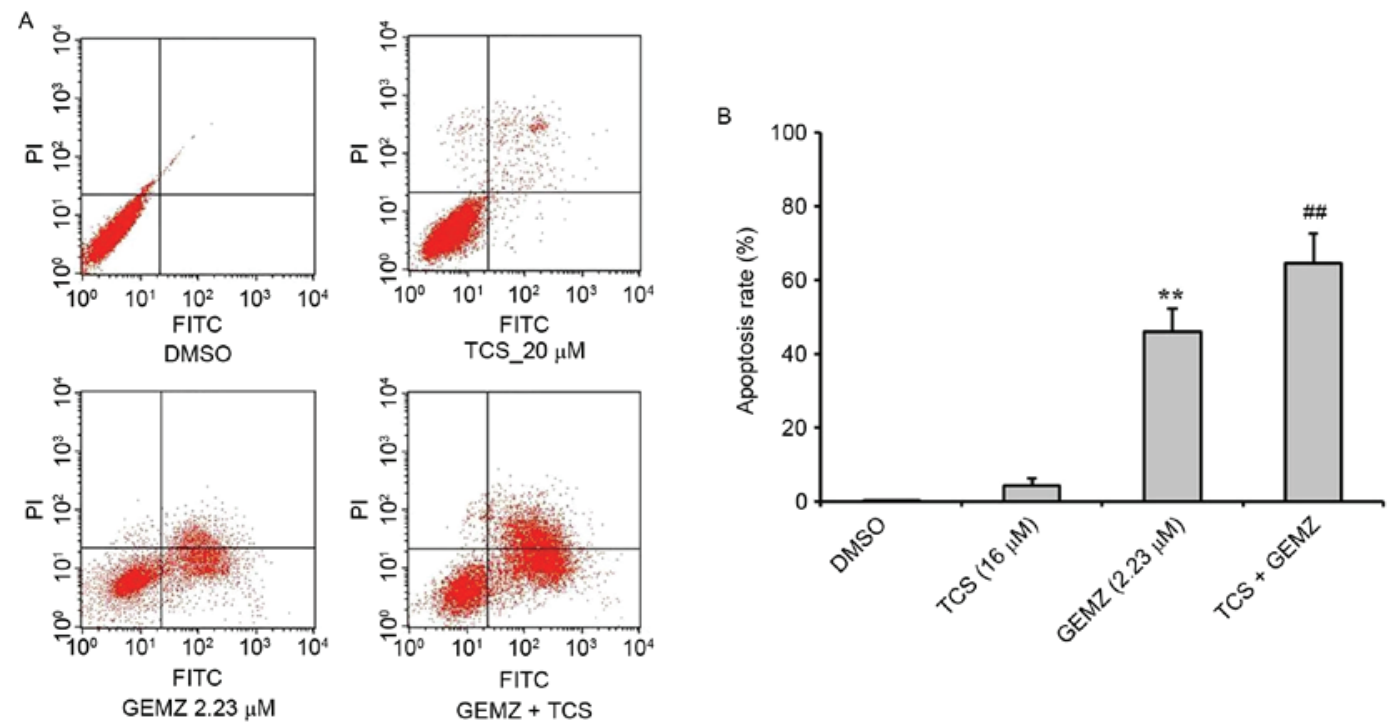

Figure 2. Effect of TCS on GEMZ-induced apoptosis in A549 cells. (A) PI staining flow cytometric analysis was used to determine the effect of TCS and/or GEMZ on apoptosis. (B) Quantification of PI-positive cells. Results are expressed as the mean \pm standard deviation for more than three independent experiments. ${ }^{* *} \mathrm{P}<0.01$ vs. DMSO group; ${ }^{\# \#} \mathrm{P}<0.01$ vs. GEMZ treatment group. TCS, trichosanthin; GEMZ, gemcitabine; PI, propidium iodide.

a marked cell growth inhibition effect with limited cell toxicity, it was used as a standard combination strategy in the following studies.

TCS increases GEMZ-induced apoptosis in A549 cells. To evaluate the function of TCS combined with GEMZ in A549 cells, an annexin/PI staining flow cytometry assay was performed to detect the mechanism of cell death in A549 cells (Fig. 2). The results revealed that GEMZ significantly induced apoptosis in A549 cells ( $\mathrm{P}<0.01$ vs. TCS treatment alone). Combined treatment of GEMZ with TCS significantly increased the apoptosis rate of A549 compared with GEMZ treatment alone $(\mathrm{P}<0.01)$. However, TCS treatment on its own did not induce apoptosis, which was consistent with the cell 

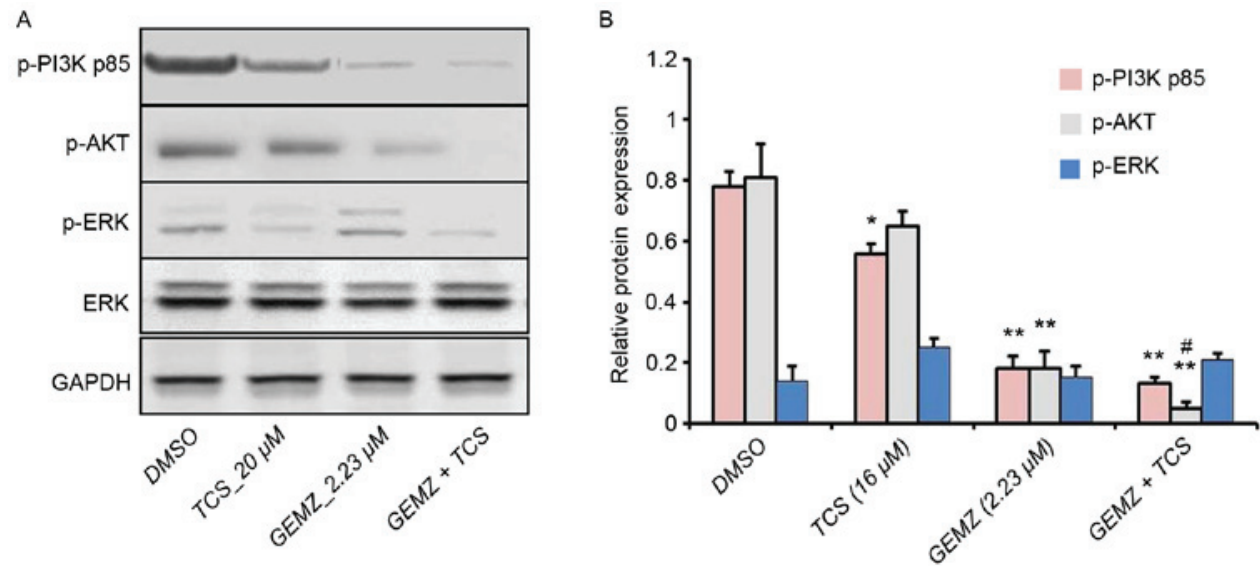

Figure 3. PI3K-AKT signaling pathway is involved in TCS- and GEMZ-induced cell death. (A) Expression of p-PI3K p85, p-AKT, p-ERK, ERK and GAPDH were analyzed by western blot analysis. (B) Densitometry analysis of the bands was detected using Bio-Rad software. Results are expressed as the mean \pm standard deviation for more than three independent experiments. ${ }^{*} \mathrm{P}<0.05,{ }^{* *} \mathrm{P}<0.01$ vs. DMSO group; ${ }^{*} \mathrm{P}<0.05$ vs. GEMZ treatment group. TCS, trichosanthin; GEMZ, gemcitabine; PI3K, phosphoinositide 3-kinase.

cytotoxic assay. The results revealed that TCS enhanced cell death induced by GEMZ by inducing A549 cell apoptosis .

Combination treatment of GEMZ with TCS suppresses the PI3K pathway in A549 cells. To further detect the underlying mechanism of combination therapy of TCS and GEMZ, western blot analysis was performed. The PI3K/AKT pathway is a classical signaling pathway involved in cell death, tumor progression, survival, metabolism, metastasis and drug resistance (25). Western blot analysis revealed that the expression level of p-AKT was significantly lower in cells treated with combination treatment of TCS and GEMZ when compared with those treated with GEMZ alone ( $\mathrm{P}<0.05$; Fig. 3). However, the levels of p-P3K p85 and p-ERK were not significantly altered. Therefore, the results indicated that PI3K signaling may be involved in TCS-enhanced GEMZ-induced cell death and apoptosis.

TCS combined with GEMZ suppresses the PI3K pathway. Insulin is able to stimulate the activation of PI3K signaling, which is involved in tumor cell survival, cell growth and proliferation (25-28). In order to validate that IGF pathway was involved in the effects of TCS and GEMZ combination treatment in A549 cells, IGF1 $(5 \mathrm{ng} / \mathrm{ml})$ was used. The cell viability assay revealed that following pretreatment with IGF1, the inhibitory rate decreased compared with combination therapy of TCS and GEMZ ( $<<0.05$; Fig. 4A). Furthermore, the expression levels of p-PI3K p85 and p-AKT were increased upon addition of IGF1 compared with combination therapy of TCS and GEMZ (Fig. 4B). The results indicated that in A549 cells, the PI3K/AKT pathway was suppressed when combination treated with TCS and GEMZ, and it was hypothesized that TCS may enhance GEMZ exerting its pharmacological effects by regulating the level of insulin.

\section{Discussion}

In recent studies, researchers have aimed to identify the potential targets of GEMZ as well as the identification of potential agents that may be used in combination with GEMZ

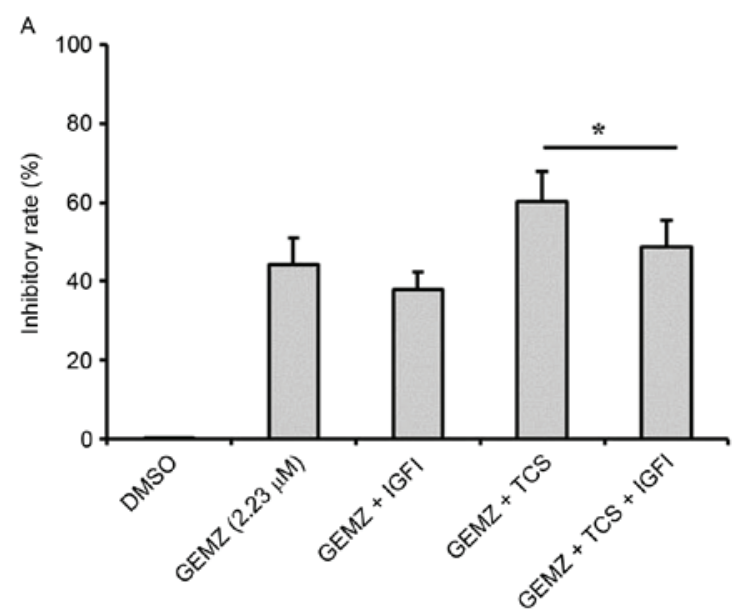

B

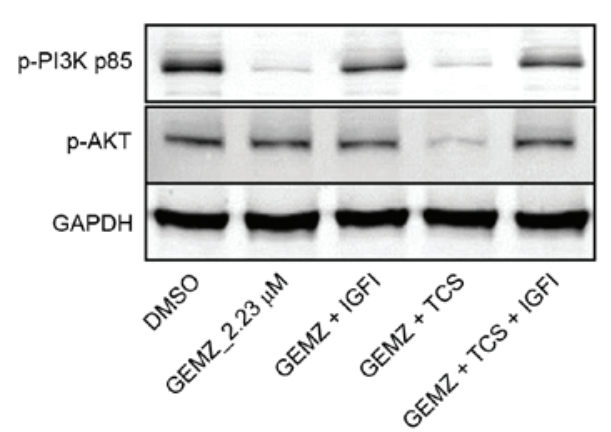

Figure 4. TCS and GEMZ suppressed the PI3K pathway by inhibiting the activity of IGF1. (A) Following the indicated treatment of TCS or GEMZ, combination treatment with GEMZ and TCS or pretreatment with IGF1 $(5 \mathrm{ng} / \mathrm{ml})$, the inhibitory rate was assessed by MTT assay. (B) Expression levels of p-PI3K p85, p-AKT and GAPDH were analyzed by western blot analysis. Results are expressed as the mean value \pm standard deviation for more than three independent experiments, ${ }^{*} \mathrm{P}<0.05$ as indicated. TCS, trichosanthin; GEMZ, gemcitabine; PI3K, phosphoinositide 3-kinase.

chemotherapy $(10,12)$. It has been previously reported that dihydroartemisinin combined with GEMZ has a synergistic interaction in A549 cells to induce apoptosis (29), and GEMZ and sorafenib has synergistic interaction in A549 cells to inhibit epidermal growth factor receptor-tyrosine kinase inhibitor 
(EGFR-TKI)-sensitive and EGFR-TKI-resistant NSCLC (30). Furthermore, piceatannol enhances the antitumor efficacy of GEMZ in A549 cells (10). In the present study, the potential effects and underlying mechanisms of combination therapy of GEMZ and TCS were investigated in A549 cells. It was demonstrated that in the A549 cell line, TCS enhanced the antitumor effects of GEMZ. Additionally, the combination treatment resulted in a significant increase in the apoptotic cell population compared with GEMZ treatment only.

The PI3K/AKT pathway is a canonical signaling pathway involved in proliferation, metabolism, protein synthesis and cell survival (25). It was also reported that the PI3K/AKT pathway was involved in cell apoptosis in numerous cell lines (31-33), such as lung cancer cell lines (34). In addition, a study by Mu et al (35) reported that GEMZ had antitumor effects in pancreatic cancer by regulating the PI3K/AKT pathway. With this in mind, the potential role of the PI3K/AKT pathway in mediating the enhancing effects of TCS on GEMZ-induced cell death was investigated in the present study. The present study revealed that TCS treatment resulted in an evident increase of apoptosis in GEMZ-treated A549 cells, and this was associated with significant downregulation of the PI3K/AKT pathway. However, the expression levels of ERK were not significantly altered. This suggests that ERK may not be involved in the cell apoptosis of A549 cells induced by GEMZ and TCS combination therapy. Then, the upstream factors of the PI3K/AKT pathway were evaluated using IGF1. Insulin signaling employs the kinase-linked cascades of PI3K/AKT and ERK $(36,37)$. Furthermore, IGF1 may mediate apoptosis and cell survival by regulating the PI3K-AKT pathway (38). In the present study, following addition of IGF1, the inhibitory rate was decreased compared with the GEMZ + TCS group, which was consistent with the results of the western blot analysis. Additionally, these results further confirmed the hypothesis that TCS exerted its synergistic pharmacological effect in GEMZ-treated NSCLC via inhibition of the PI3K/AKT pathway.

Drug resistance is a major problem for treatment with GEMZ. A large number of studies have indicated that $\mathrm{PI} 3 \mathrm{~K} / \mathrm{AKT}$ signaling is involved in chemotherapy drug sensitivity or drug resistance (39-41). In the present study, TCS enhanced GEMZ to suppress the expression level of PI3K and AKT, and thus it may be hypothesized that, on one hand, TCS enhances GEMZ-induced apoptosis via regulating the PI3K/AKT pathway; and on the other hand, TCS combined with GEMZ could reduce drug resistance via the PI3K/AKT pathway. However this hypothesis requires further investigation. Various clinical research ranging between phase I and III trails have focused on combination therapy of GEMZ with insulin inhibitors $(42,43)$ in order to reduce GEMZ chemoresistance. Insulin has been demonstrated to be capable of regulating PI3K/AKT activity (43). This may indicate that TCS combined with GEMZ could not only induce apoptosis via PI3K/AKT signaling, but also reduce GEMZ-resistance in A549 cells via this signaling.

In conclusion, the present study demonstrated that TCS was capable of significantly enhancing the cytotoxic and apoptotic effects of GEMZ in A549 NSCLC cells via regulating the PI3K/AKT pathway. These results may provide a potential rational basis for a combination strategy for chemotherapy treatment of NSCLC.

\section{References}

1. Gompelmann D, Eberhardt R and Herth FJ: Advanced malignant lung disease: What the specialist can offer. Respiration 82: 111-123, 2011.

2. Katlic MR, Facktor MA, Berry SA, McKinley KE, Bothe A Jr and Steele GD Jr: ProvenCare lung cancer: A multi-institutional improvement collaborative. CA Cancer J Clin 61: 382-396, 2011.

3. Siegel R, Ma J, Zou Z and Jemal A: Cancer statistics, 2014. CA Cancer J Clin 64: 9-29, 2014.

4. Siegel R, Naishadham D and Jemal A: Cancer statistics, 2013. CA Cancer J Clin 63: 11-30, 2013.

5. Malapelle U, Pisapia P, Rocco D, Smeraglio R, di Spirito M, Bellevicine $\mathrm{C}$ and Troncone G: Next generation sequencing techniques in liquid biopsy: Focus on non-small cell lung cancer patients. Transl Lung Cancer Res 5: 505-510, 2016.

6. Langer F, Helsberg K, Schütte WH and Leschinger MI: Gemcitabine in the first line therapy of advanced and metastatic non-small-cell lung carcinoma (NSCLC): Review of the results of phase III studies. Onkologie 28 (Suppl 1): S1-S28, 2005 (In German).

7. Laskin JJ and Sandler AB: First-line treatment for advanced non-small-cell lung cancer. Oncology (Williston Park) 19: 1671-1680, 2005.

8. Gallelli L, Nardi M, Prantera T, Barbera S, Raffaele M, Arminio D, Pirritano D, Colosimo M, Maselli R, Pelaia G, et al: Retrospective analysis of adverse drug reactions induced by gemcitabine treatment in patients with non-small cell lung cancer. Pharmacol Res 49: 259-263, 2004.

9. Wang B and Cui J: Treatment of mid-late stage NSCLC using sodium cantharidinate/vitamin B6/GP regimen in clinic. J Cancer Res Ther 10 Suppl 1: C79-C81, 2014.

10. $\mathrm{Xu} \mathrm{B}$ and Tao ZZ: Piceatannol enhances the antitumor efficacy of gemcitabine in human A549 non-small cell lung cancer cells. Oncol Res 22: 213-217, 2014.

11. Karampeazis A, Vamvakas L, Kentepozidis N, Polyzos A, Chandrinos V, Rigas G, Christofyllakis C, Kotsakis A, Hatzidaki D, Pallis AG and Georgoulias V: Biweekly carboplatin plus gemcitabine as first-line treatment of elderly patients with advanced squamous non-small-cell lung cancer: A multicenter phase I-II trial by the hellenic oncology research group. Clin Lung Cancer 17: 543-549, 2016.

12. Yoshitomi S, Taira N, Doihara H, Mizoo T, Nogami T, Iwamoto T, Motoki T, Shien T, Ogasawara Y, Matsuoka J, et al: A phase 1, dose-finding and pharmacokinetic study of gemcitabine with nab-paclitaxel in patients with metastatic breast cancer. Cancer Chemother Pharmacol 78: 289-294, 2016.

13. Sha O, Niu J, Ng TB, Cho EY, Fu X and Jiang W: Anti-tumor action of trichosanthin, a type 1 ribosome-inactivating protein, employed in traditional Chinese medicine: A mini review. Cancer Chemother Pharmacol 71: 1387-1393, 2013.

14. Au TK, Collins RA, Lam TL, Ng TB, Fong WP and Wan DC: The plant ribosome inactivating proteins luffin and saporin are potent inhibitors of HIV-1 integrase. FEBS Lett 471: 169-172, 2000.

15. Byers VS, Levin AS, Malvino A, Waites L, Robins RA and Baldwin RW: A phase II study of effect of addition of trichosanthin to zidovudine in patients with HIV disease and failing antiretroviral agents. AIDS Res Hum Retroviruses 10: 413-420, 1994.

16. Sha O, Yew DT, Ng TB, Yuan L and Kwong WH: Different in vitro toxicities of structurally similar type I ribosome-inactivating proteins (RIPs). Toxicol In Vitro 24: 1176-1182, 2010.

17. $\mathrm{Ng} \mathrm{TB}$, Wong JH and Wang H: Recent progress in research on ribosome inactivating proteins. Curr Protein Pept Sci 11: 37-53, 2010.

18. Zhu Y, Sun Y, Cai Y, Sha O and Jiang W: Trichosanthin reduces the viability of SU-DHL-2 cells via the activation of the extrinsic and intrinsic apoptotic pathways. Mol Med Rep 13: 403-411, 2016.

19. Ouyang DY, Chan H, Wang YY, Huang H, Tam SC and Zheng YT: An inhibitor of c-Jun N-terminal kinases (CEP-11004) counteracts the anti-HIV-1 action of trichosanthin. Biochem Biophys Res Commun 339: 25-29, 2006.

20. Huang H, Chan H, Wang YY, Ouyang DY, Zheng YT and Tam SC: Trichosanthin suppresses the elevation of p38 MAPK and Bcl-2 induced by HSV-1 infection in Vero cells. Life Sci 79: $1287-1292,2006$ 
21. Wang P, Yan H and Li JC: CREB-mediated Bcl-2 expression in trichosanthin-induced Hela cell apoptosis. Biochem Biophys Res Commun 363: 101-105, 2007.

22. Li M, Chen F, Liu CP, Li DM, Li X, Wang C and Li JC: Dexamethasone enhances trichosanthin-induced apoptosis in the HepG2 hepatoma cell line. Life Sci 86: 10-16, 2010.

23. Zhang D, Chen B, Zhou J, Zhou L, Li Q, Liu F, Chou KY, Tao L and Lu LM: Low concentrations of trichosanthin induce apoptosis and cell cycle arrest via c-Jun N-terminal protein kinase/mitogen-activated protein kinase activation. Mol Med Rep 11: 349-356, 2015.

24. Li CT, Lin CH, Kao TY, Wu MF, Yeh CS, Yeh KT and Ko JL: The mechanisms of action of Tianhua $\left({ }^{\mathrm{TM}}\right)$ on antitumor activity in lung cancer cells. Pharm Biol 48: 1302-1309, 2010.

25. Bhaskar PT and Hay N: The two TORCs and Akt. Dev Cell 12 487-502, 2007

26. Chen J: Is Src the key to understanding metastasis and developing new treatments for colon cancer?. Nat Clin Pract Gastroenterol Hepatol 5: 306-307, 2008.

27. Ozes ON, Mayo LD, Gustin JA, Pfeffer SR, Pfeffer LM and Donner DB: NF-kappaB activation by tumour necrosis factor requires the Akt serine-threonine kinase. Nature 401: 82-85, 1999.

28. Wullschleger $\mathrm{S}$, Loewith $\mathrm{R}$ and Hall MN: TOR signaling in growth and metabolism. Cell 124: 471-484, 2006.

29. Zhao C, Gao W and Chen T: Synergistic induction of apoptosis in A549 cells by dihydroartemisinin and gemcitabine. Apoptosis 19 : 668-681, 2014

30. Li J, Pan YY and Zhang Y: Synergistic interaction between sorafenib and gemcitabine in EGFR-TKI-sensitive and EGFR-TKI-resistant human lung cancer cell lines. Oncol Lett 5 : 440-446, 2013

31. Li T: Pacilitaxel induces human nasopharyngeal carcinoma cell line CNE2 apoptosis and growth inhibition by suppressing PI3K/AKT/p53 signaling pathway. Lin Chung Er Bi Yan Hou Tou Jing Wai Ke Za Zhi 29: 2147-2150, 2015 (In Chinese).

32. Lu D, Qian J, Li W, Feng Q, Pan S and Zhang S: $\beta$-hydroxyisovaleryl-shikonin induces human cervical cancer cell apoptosis via PI3K/AKT/mTOR signaling. Oncol Lett 10 : 3434-3442, 2015.

33. Zhao J, Zhang ZR, Zhao N, Ma BA and Fan QY: VEGF silencing inhibits human osteosarcoma angiogenesis and promotes cell apoptosis via PI3K/AKT signaling pathway. Cell Biochem Biophys 73: 519-525, 2015
34. Jin H, Qiao F, Wang Y, Xu Y and Shang Y: Curcumin inhibits cell proliferation and induces apoptosis of human non-small cell lung cancer cells through the upregulation of miR-192-5p and suppression of PI3K/Akt signaling pathway. Oncol Rep 34 : 2782-2789, 2015.

35. Mu GG, Zhang LL, Li HY, Liao Y and Yu HG: Thymoquinone pretreatment overcomes the insensitivity and potentiates the antitumor effect of gemcitabine through abrogation of Notch1, $\mathrm{PI} 3 \mathrm{~K} / \mathrm{Akt} / \mathrm{mTOR}$ regulated signaling pathways in pancreatic cancer. Dig Dis Sci 60: 1067-1080, 2015.

36. Yoon SH, Ramalingam $M$ and Kim SJ: Insulin stimulates integrin-linked kinase in UMR-106 cells: Potential role of heparan sulfate on syndecan-1. J Recept Signal Transduct Res 35: 613-617, 2015.

37. Ju Ha H and Kim SJ: Association of insulin receptor and syndecan-1 by insulin with activation of ERK I/II in osteoblast-like UMR-106 cells. J Recept Signal Transduct Res 33: 37-40, 2013.

38. Zhang QY, Wang L, Song ZY and Qu XJ: Knockdown of type I insulin-like growth factor receptor inhibits human colorectal cancer cell growth and downstream PI3K/Akt, WNT/ $\beta$-catenin signal pathways. Biomed Pharmacother 73: 12-18, 2015

39. Liu Q, Li X, Li C, Zheng Y and Peng G: 1-Deoxynojirimycin alleviates insulin resistance via activation of insulin signaling PI3K/AKT pathway in skeletal muscle of $\mathrm{db} / \mathrm{db}$ mice. Molecules 20: 21700-21714, 2015.

40. Ma Y, Zhang P, Gao Y, Fan H, Zhang $M$ and Wu J: Evaluation of AKT phosphorylation and PTEN loss and their correlation with the resistance of rituximab in DLBCL. Int J Clin Exp Pathol 8: 14875-14884, 2015.

41. Deng QF, Su BO, Zhao YM, Tang L, Zhang J and Zhou CC: Integrin $\beta 1$-mediated acquired gefitinib resistance in non-small cell lung cancer cells occurs via the phosphoinositide 3-kinase-dependent pathway. Oncol Lett 11: 535-542, 2016.

42. Awasthi N, Zhang C, Ruan W, Schwarz MA and Schwarz RE BMS-754807, a small-molecule inhibitor of insulin-like growth factor-1 receptor/insulin receptor, enhances gemcitabine response in pancreatic cancer. Mol Cancer Ther 11: 2644-2653, 2012.

43. Okusaka T, Ikeda M, Fukutomi A, Kobayashi Y, Shibayama K, Takubo T and Gansert J: Safety, tolerability, pharmacokinetics and antitumor activity of ganitumab, an investigational fully human monoclonal antibody to insulin-like growth factor type 1 receptor, combined with gemcitabine as first-line therapy in patients with metastatic pancreatic cancer: A phase 1b study. Jpn J Clin Oncol 44: 442-447, 2014. 